\title{
Circulação internacional de modelos de formação
}

\author{
Guilherme Simões Gomes JÚnior
}

\begin{abstract}
RESUMO
$\mathrm{O}$ artigo faz parte de um conjunto de estudos sobre a articulação social de práticas letradas e artísticas. Trata-se da biblioteca da Academia Imperial das Belas-Artes no Rio de Janeiro no estado em que se encontrava em meados do século XIX. Formada por iniciativas de Félix-Émile Taunay e Manuel Araújo Porto-Alegre, a biblioteca é exemplo da circulação internacional de modelos de formação artística. São examinados o ambiente, a decoração do recinto e o sistema de pensamento pressuposto no acervo.
\end{abstract}

PALAVRAS-CHAVE: biblioteca da Academia Imperial das Belas-Artes;

Félix-Émile Taunay; Manuel Araújo Porto-Alegre; formação artística.

\section{SUMMARY}

The paper is part of a set of studies on the social articulation of literate and artistic practices. It deals with the library of Academia Imperial das Belas-Artes (Imperial Academy of Fine Arts) in Rio de Janeiro in the state it was in the middle of the 19th century. Created on the initiative of Félix-Émile Taunay and Manuel Araújo Porto-Alegre, the library is one of the expressions of the international circulation of artistic education models. The study analyzes the space, the place's decoration and the system of thought underlying the book collection.

KEYWORDS: library of Academia Imperial das Belas-Artes; FélixÉmile Taunay; Manuel Araújo Porto-Alegre; artistic education models.

[1] Sobre as "vidas de artistas" em Portugal e no Brasil, ver Gomes Júnior, G. S. "Vidas de artistas: Portugal e Brasil". Revista Brasileira de Ciências Sociais, v. 22/64. São Paulo, Anpocs, 2007.
A Academia Imperial das Belas-Artes (Aiba) e o rico ambiente artístico do Rio de Janeiro no século XIX formaramse em um processo marcado por translados e descontinuidades, que resultou das guerras e da trama de relações internacionais tecida nos escombros da grande transformação desencadeada pela Revolução Francesa.

Apesar de instituídos em realidade social bastante diversa, os padrões artísticos reproduzidos no Brasil seguiram uma lógica que é comprensível pelo fato de fazerem parte de um complexo europeu que se configurou em redes muito antes da emergência das instituições e dos eventos aqui tratados. A própria idéia de escola artística, ancorada em um lugar determinado e portadora de características singulares, foi gestada em um contexto em que a circulação de artistas era um fenômeno bastante generalizado. O gênero literário das vidas de artistas ${ }^{1}$, 
que proliferou com a criação das academias, teve papel importante na fixação da idéia de escola, na medida em que as biografias foram agrupadas em linhagens, umas às outras opostas e complementares, mas todas enraizadas em um determinado solo, quase sempre identificado a uma cidade. No entanto, a constituição imaginária das escolas aconteceu no momento em que as corporações urbanas de praticantes das artes do desenho perdiam seus monopólios e privilégios. É nesse contexto que aconteceu a proliferação do artista de corte e das academias de arte. Se estas também foram instituições identificadas a cidades, seus padrões de reprodução pressupunham um cenário mais amplo, marcado por constantes trocas e deslocamentos. E não se trata aqui apenas da viagem à Itália, momento essencial da formação do artista moderno, mas de inúmeras temporadas de prestação de serviços em diversas cortes européias, assim como de transferências permanentes. Já no século XVI e, sobretudo, no XVII a realidade das academias pressupunha um espaço de relações internacionais onde circulavam não apenas pessoas, mas também obras, livros e modelos educativos.

É nesse cenário que a biblioteca começa a fazer sentido, mas não somente em seu caráter propedêutico. Que a biblioteca pode ser útil para o ensino em um âmbito em que regras e técnicas são essenciais, não parece haver dúvida. Mas, mais do que isso, há que se levar em conta o ideal do artista letrado que começa a se construir a partir de Alberti, tendo como modelo o poeta erudito da Antigüidade. Reciclado no Renascimento, esse modelo pressupunha um artista com domínio das principais matérias das artes liberais, os números e formas da aritmética e da geometria, os princípios da poética e da retórica para instruí-lo no âmbito das narrativas da pintura de história. E a esses foram se agregando outros saberes em constante acumulação.

No início do século XIX, os livros dedicados à literatura artística já se dispunham em diversas camadas, e o acervo da biblioteca da Academia Imperial das Belas-Artes no Rio de Janeiro constitui-se em um bom exemplo dessas sobreposições e dos efeitos de longa duração visíveis no conjunto. Apesar de a biblioteca aparentar ser um corpo estático, há nela uma história pressuposta, seja porque o conjunto é composto por obras distribuídas por suas datas de edição em pouco mais de três séculos, seja porque em obras modernas são retomadas partes, preceitos, exemplos ou noções de suas ancestrais, em um jogo de diferenças e repetições. No entanto, o entendimento da natureza do conjunto não é suficiente para esclarecer aspectos essenciais do uso dos livros, pois, como se sabe, uma biblioteca é composta também por muitos livros que não são lidos, e lá figuram como escombros ou tesouros intactos. Apesar disso, a biblioteca pode ser tomada como índice da inteligência da instituição que a abriga, mesmo que essa inteligência indique apenas uma potencialidade. Daí a importância de se 
acompanhar o trabalho da formação da biblioteca por parte daqueles que dirigiram a Academia Imperial das Belas-Artes, interferindo na composição do acervo e incentivando a leitura dos livros. Na medida em que a escola possui um caráter normativo, a biblioteca reveste-se de autoridade e adquire o caráter de dispositivo, pois nela se encontram os preceitos que fundamentam a artee seus fazeres. É nela em que estão as obras clássicas, o cânone da literatura artística que merece figurar no currículo e participar da rotina dos ateliês.

\section{FÉLIX-ÉMILE TAUNAY E ARAÚJO PORTO-ALEGRE}

Não são muitas as notícias que permitem reconstituir a história da biblioteca da Academia Imperial das Belas-Artes. Sabe-se, por um escrito de Araújo Porto-Alegre (1806-1879), que a biblioteca estava localizada em um salão no primeiro andar do edifício projetado por Grandjean de Montigny. Em posição de destaque pois, no princípio, só havia pavimento superior na parte central do edifício, cuja fachada tinha a forma de um templo jônico. Depois de 1882, o Palácio da Academia ganhou um segundo pavimento em toda a sua extensão, e a biblioteca passou a ocupar uma sala pouca coisa menor, na ala direita do segundo piso, com três grandes janelas. Do edifício original, a única coisa que sobrou foi seu frontispício, que hoje se encontra preservado no Jardim Botânico do Rio de Janeiro.

$\mathrm{Na}$ época em que Araújo Porto-Alegre dirigiu a Academia (18541857), a biblioteca foi organizada e equipada com o mobiliário adequado; e Léon Pallière Grandjean Ferreira realizou para seu teto uma "alegoria à reforma dos estudos", pintura que foi elogiosamente descrita por Gonzaga Duque:

A composição é de uma simplicidade tocante, de uma preciosa pureza de linhas que lembra, em harmonia e singeleza, a severidade das linhas gregas. O colorido é simples, rico em limpidez, feliz na tonalidade. O caráter decorativo relaciona-se perfeitamente com ofim a que a sala é destinada, e com o caráter do edifício. Nem mais um esperdício de linha, uma prolixidade, um desgarre de pincel. Sob a cúpula azul do céu estão reunidas a escultura, a arquitetura e a pintura. A arquitetura, a grande arte social por excelência, figura no centro, sobre uma grande cadeira grega, tendo ao lado as co-irmãs. As expressões dessas três figuras, delineadas pelo molde formoso e ao mesmo tempo grave de onde saíram as peregrinas belezas do paganismo, se traduzem em serenidade, saber e talento. Sobretudo, a que preside a reunião patenteia,

[2] Estrada, Luiz Gonzaga Duque. Arte Brasileira. Introd. e notas de Tadeu Chiarelli. Campinas: Mercado das Letras, 1995, p. 126. nos corretíssimos traços fisionômicos, galhardo talento e soberana calma ${ }^{2}$.

Porto-Alegre, que instruiu Léon Pallière sobre o que deveria figurar na pintura do teto, foi o idealizador e o executor da reforma do ensino 
da Academia, que começou a ser posta em prática em sua gestão e veio a ser conhecida como Reforma Pedreira, em homenagem ao ministro dos Negócios do Império, ao qual a Academia estava subordinada.

Pelo conteúdo do ofício enviado ao ministério, no qual Porto-Alegre solicita recursos para as instalações, tem-se a idéia de que até então não havia biblioteca: "[...] tenho a honra de propor a V. Exc. a criação de uma biblioteca especial nesta Academia a fim de que os mestres, discípulos e amadores aí encontrem o que a pobreza os impede de adquirir [...]"3. No entanto, o mesmo ofício faz referência a um bibliotecário já em atividade; e os livros, que foram dispostos neste novo ambiente, também já existiam, pois há notícia deles em documentos anteriores.

Félix-Émile Taunay já falava explicitamente da biblioteca em seu discurso na abertura do ano letivo de 1835, no início de sua gestão como diretor da Academia. Referia-se ao "sr. Joaquim Vieira da Silva e Souza, atento à formação da nossa biblioteca" e às suas gestões para conseguir da Biblioteca Pública a remessa de exemplares de livros de arte que nela existissem em duplicata4.

Esta demanda por livros em duplicata reaparece mais tarde nos escritos de Porto-Alegre em que tratou do mesmo assunto. Mas nãoé certo que a biblioteca da Aiba tenha conseguido tais transferências.

No que diz respeito à coleção de livros da Aiba, Alfredo Galvão publicou em 1957 uma separata na qual transcreve um "Velho catálogo sem data e manuscrito, cujas folhas estão rubricadas por Félix-Émile Taunay" 5 ,em que constam os livros pertencentes à Academia, provavelmente em 1850. Trata-se de um documento precioso no qual constam 83 títulos, quase todos eles acompanhados do nome do autor, lugare data de publicação. Além disso, na margem esquerda da lista, aparece a referência ao doador ou à procedência da obra. Na sua maioria, estas notícias indicam que os livros foram ou doados pelo diretor, o próprio Taunay, ou adquiridos por um "Fundo da Academia", o que faz pensar que nos dezessete anos da gestão de Taunay houve um esforço sistemático para equipar a escola com referências bibliográficas importantes para o ensino, para o próprio uso de professores, de alunos e, provavelmente, de artistas que gravitavam em torno da Academia.

A este documento, que dá a idéia do estado da biblioteca em 1850 , agrega-se outro que faz referência à doação de 23 títulos (40 volumes) feita por Porto-Alegre em 1859, data que corresponde à sua partida do Brasil, para as sucessivas missões diplomáticas que ocuparam os últimos vinte anos de sua vida ${ }^{6}$.

Nestes dois documentos, tem-se, portanto, a referência a 106 títulos que foram acessíveis na Academia em meados do século XIX, o que é um bom ponto de partida para se ter uma visão dos recursos teóricos e práticos que estavam ao alcance de professores e alunos na época em que a Academia atingia sua maioridade.
[3] Porto-Alegre, M.A. "Ofício" [datado de 05/01/1855]. In: Galvão, A. (org.) "Manuel de Araújo Porto-Alegre: sua influência na Academia Imperial das Belas-Artes e no meio artístico do Rio de Janeiro". Revista do Patrimônio Histórico e Artístico Nacional 14. Rio de Janeiro, 1959, p. 75.

[4] Apud Santos, Francisco Marques dos. "Subsídios para a história das Belas-Artes no Segundo Reinado. As Belas-Artes na Regência". Estudos Brasileiros, vol. 9, nos 25-2627. Rio de Janeiro: Instituto de Estudos Brasileiros, 1942, p. 42.

[5] Universidade do Brasil - Escola Nacional de Belas-Artes. Catálogo da Biblioteca com indicação das obras raras ou valiosas. Rio de Janeiro, 1957.

[6] Museu d.João VI, Minuta de ofício da Aiba solicitando permissão para aceitar a oferta de 40 volumes feita por Porto-Alegre à Biblioteca da Aiba [Baiba]. Contém relação das obras doadas. 10/09/1859 [documento avulso 4350]. Porto-Alegre foi cônsul brasileiro em Berlim, Dresden e, por fim, em Lisboa, onde faleceu. 
[7] O original de Bardwell do qual foi feita a tradução não consta das listas dos livros da Baiba. A referência é: Bardwell, Thomas. The practice of painting and perspective made easy. Londres: Printed by S. Richardson, for the autor, 1756 .
[8] Este livro de De Piles, de evidente caráter didático, aparece como tendo sido "mis en lumière par François Tortebat, d'après le choix, fait par R. de Piles, des figures du Traité d'anatomie de Vesale, dessinés par le Titien". Andreas Vesalius foi médico nascido em Bruxelas, professor de anatomia em Louvain. Em 1555 publicou De humanis corpori fabrica (ver Abrégé d'anatomie, accomodé aux arts de peinture et de sculpture par M. de Piles. Chez C.-A. Jombert, 1765).
Apesar destes documentos, pouco se sabe acerca do uso ordinário dos livros. Dos 83 títulos que constam do catálogo redigido por Taunay, 49 são franceses (a língua e a edição); 22 italianos; 7 portugueses ou brasileiros; 2 latinos; 1 espanhol e 1 inglês. Ao contrário deste catálogo, no qual a grande maioria das informações bibliográficas é bastante completa, a lista das doações de Porto-Alegre de 1859 encontraseem documento manuscrito, com referência aos autores e aos títulos dos livros, mas o copista traduziu todos os títulos, além de não dar qualquer outra informação sobre as línguas em que estão escritos. Mas, mesmo assim, é perceptível também a predominância de livros franceses e italianos. Se estas duas últimas eram na época as "línguas gerais" dos artistas, há no entanto indícios de que os jovens alunos as desconheciam. Daí o esforço de Taunay no sentido de tornar acessível parte desta literatura por meio da tradução de alguns livros considerados estratégicos para o ensino. $O$ próprio Taunay traduziu do inglês Arte de pintar a óleo conforme a prática de Bardwell baseada sobre o estudo e a imitação dos primeiros mestres das escolas italiana, inglesa e flamenga 7 . Traduziu e editou também um compêndio de vários autores chamado Epítome de anatomia relativo às belas-artes seguido de um compêndio de fisiologia das paixões e de algumas considerações gerais sobre as proporções com as divisões do corpo humano; oferecido aos alunos da Imperial Academia das BelasArtes do Rio de Janeiro. Esta tradução, na parte dedicada à osteologia e miologia - ossos e músculos — , reproduz textos de Roger de Piles (1635-1709); na parte relativa à fisiologia das paixões reproduz estudos de Charles Le Brun (1619-1690); e sobre o tópico das proporções retira as idéias gerais de Aubin Louis Millin de Grandmaison (17591818), e a parte mais prática é traduzida de um manual do graveur en taille douce Gérard Audran (1640-1703).

Sobre essa seqüência de autores, é importante lembrar que De Piles, Le Brun e Audran foram artistas e letrados da época de Luís XIV, representantes da fase inicial da Académie Royale de Peinture et Sculpture em Paris, fundada em 1648, sob os auspícios do cardeal Mazarino.Já Millin é um representante típico dos grandes eruditos do Institut de France no início do XIX.Versado em artes e línguas antigas, Millin é o autor do altamente instrutivo Dictionnaire des beaux-arts, de 1806, livro que consta do catálogo elaborado por Taunay.

Nas listas de livros pertencentes à Baiba não há referências a De Piles e Le Brun, mas o prefácio da tradução feita por Taunay indica que, do primeiro, foram traduzidos trechos do livro Abrégé d'anatomie accomodé aux arts de peinture et de sculpture, que teve reedição em 1798. Este livro de De Piles tem por base uma seleção de figuras desenhadas por Ticiano para o famoso tratado de anatomia de Andreas Vesalius (1514-1565)8.

De Le Brun não fica clara a fonte da tradução, que pode ter tido origem em uma de suas tantas conferências na Academia que abordaram 
o tema das paixões aplicadas às belas-artes, que foram objeto de diversas publicações:Méthode pour apprendre à dessiner les passions (1713); Conférence de M.Le Brunsurl'expression générale etparticulière despassions (1713); Expressions despassions de lâmereprésentéesen plusieurstêtes gravéesd'aprèsles dessins de feu M. Le Brun (1727), textos que circularam por muito tempo no ambiente das academias em suas formas originais ou em epítomes.

Quanto à parte relativa a Audran, na tradução de Taunay a fonteé o livro Les proportions du corps humain, mesurées sur les plus belles figures de l'Antiquité, de 1683, reeditado em 1801, título que também consta no catálogo da Baiba.

Esse é talvez o melhor exemplo dos efeitos de longa duração presentes no interior da biblioteca: o compêndio didático sobre anatomia e fisiologia das paixões traduzido e organizado por Taunay contém quatro camadas sobrepostas: da primeira metade do século XVI, Vesalius e Ticiano; do final do século XVII, De Piles, Le Brun e Audran; do início do século XIX, Milin de Grandmaison; por fim, de 1837, a própria iniciativa de Taunay de juntar tudo isso e recolocar em funcionamento no âmbito da academia no Rio de Janeiro.

Essas edições da Academia no Rio de Janeiro buscavam não só oferecer recursos para seus próprios trabalhos internos, mas também fornecer subsídios para outras instituições, como é explicitado em um de seus prefácios:

A Academia entende assim preencher, como estabelecimento central, um dos fins de sua existência, procurando, debaixo da aprovação do Governo, espalhar elementos de instrução capazes de despertar o gênio em qualquerparte em que se acha, eporele promovero renome nacional na cultura das Artes?.

Estas iniciativas de Taunay datam de 1836 e 1837 , o que demonstra que desde o início de sua gestão como diretor (1834-1851) a biblioteca já era considerada um lugar estratégico na rotina acadêmica.

Por mais variados que sejam os livros, seus assuntos, seus doadores, pode-se intuir no exame da biblioteca um sistema de conhecimento.Um ponto de partida para entendê-lóverificar os autores com maior número de títulos. Winckelmann (1717-1768), Quatremère de Quincy (1755-1849) e Bartolomeo Pinelli (1781-1835) ocupam posição de destaque.

De Winckelmann, que no universo acadêmico era ainda a mais incontestável autoridade em assuntos artísticos, principalmente antigos mas também modernos, no catálogo de Taunay consta apenas Monumentiantichi inediti; mas, com as doações de Porto-Alegre de 1859 , entraram na biblioteca Histoire de l'art chez les Anciens (três volumes); Remarques surl'architecture des Anciens; Recueil des différentes pièces surl'art;
[9] Apud Galvão, A. (org.). "Felix Emílio Taunay e a Academia das Belas-Artes". Revista do Patrimônio Histórico e Artístico Nacional 16. Rio de Janeiro, 1968, pp.141-142. 
[10] Cinco destas obras entraram na biblioteca na doação de 1859; enquanto duas, as vidas de Rafael e Michelangelo, já estavam lá, e o catálogo de Taunay indica Porto-Alegre como doador.

[11] A introdução de História da Arte no currículo já havia sido idealizada por Taunay, mas foi Porto-Alegre quem formalizou sua inclusão. Mas, como tantas tentativas de Porto-Alegre, esta também demorou muito para tornar-se realidade. Apenas em 1869 foi designado um professor para a referida disciplina: Pedro Américo, que nela atuou apenas durante esse ano. Por todo o século XIX o funcionamento desta cadeira foi precário e o número de alunos muito reduzido (Ver Fernandes, Cybele V. N. "O ensino de pintura e escultura na Academia Imperial de Belas-Artes". In: Pereira, Sonia Gomes (org.). 185 anos de Escola de Belas Artes. Rio de Janeiro: UFRJ, 2002). e uma obra que é referida como "Coleção de Cartas", que é, provavelmente, Recueil de lettres sur les découvertes faites à Herculanum.

De Quatremère de Quincy, que foi secretário perpétuo da classe de Belas-Artes do Institut de France entre 1816 e 1839, constam Histoire de la vie et des ouvrages des plus célèbres architectes du XI ${ }^{e}$ siècle jusqu'à la fin du XVIII (dois volumes); Histoire de la vie et des ouvrages de Raphaël; Histoire de la vie et des ouvrages de Michel-Ange Buonarroti; Monuments et ouvrages d'art antiques restitués d'après les descriptions des écrivains grecs et latins, et acompagnés de dissertations archeologiques (catálogo de Taunay); e Canova et ses ouvrages ou Mémoires historiques sur la vie et les ouvrages de ce célèbre artiste (doação de Porto Alegre de 1859).

De Bartolomeo Pinelli, gravador romano formado no ambiente da Academia de San Luca, famoso por seus desenhos de costumes e cenas populares, constam no catálogo da Baiba quatro títulos:L'Eneide di Virgilio tradotta da Clemente Bondi inventata ed incisa all'acquaforte da Bartolomeo Pinelli; Raccolta di cento costumi antichi ricavati dai monumenti e degli autore antichi designati ed incise all'acquaforte da Bartolomeo Pinelli; Nuova raccolta di cinquanta motivi pittoresche e costumi di Roma; e Raccolta di cinquanta costumi di Napoli.

No cânone da Academia Imperial das Belas-Artes destacam-se, portanto, os dois mais importantes teóricos do neoclassicismo dos séculos XVIII e XIX. Cinco títulos de Winckelmann, cinco de Quatremère de Quincy, dos quais sete entraram na biblioteca por doação de Porto-Alegre $^{10}$. O fato de este aporte bibliográfico estar associado a ele é coerente com sua trajetória de artista letrado, que se dedicou à história, às biografias de artistas, à estética e à arqueologia, e foi sem dúvida o mais relevante pensador das artes no Brasil de seu tempo.Écoerente também com um dos tópicos da reforma da Academia, realizada sob sua gestão, que criou a disciplina de História das Belas-Artes, Estética e Arqueologia ${ }^{11}$.

Quanto aos quatro livros de Bartolomeo Pinelli, pode-se dizer que fazem parte de um significativo conjunto dedicado a imagens italianas, certamente a região do mundo mais bem documentada na biblioteca. Os livros de Pinelli fazem série com Palais, maisons et autres édifices modernes [de Roma], de Percier \& Fontaine; Architecture toscane, de Grandjean de Montigny; Pisa illustrata, de Alessandro Marrona; Le mura di Roma, de Antonio Nibby; e um certo Esboços da cidade de Nápoles, de autor desconhecido; além dos livros com ilustrações de pintura e escultura de coleções italianas.

Afora esses, nenhum outro autor possui mais de dois títulos na biblioteca. O que leva a pensar que, para Taunay, o assunto era mais importante do que o autor; ou, a dizer de outra forma, a função do livro como eventual recurso pedagógico era mais visada por Taunay do que a autoridade daquele que tem seu nome inscrito na obra, preocupação mais típica de um artista letrado, de um teórico, como foi Porto-Alegre. 
Outra forma de entrada no universo da biblioteca é por meio de sua divisão em áreas, que direta ou indiretamente remetem às divisões do ensino. Como está explícito na alegoria pintada por Léon Pallière no teto da biblioteca, a Academia seguia o modelo, canônico desde Vasari, que contemplava as três artes do desenho: Arquitetura, Pintura e Escultura; e os livros distribuíam-se por estas três áreas, complementadas pelas matérias que faziam parte da formação geral do artista.

Para a formação do arquiteto havia uma miscelânea de livros que podem ser classificados em três grandes conjuntos: os dogmáticos, os técnicos e os exemplares. Por dogmáticos se entende aqui aqueles que sistematizavam conhecimentos antigos, que eram a base da formação neoclássica, e tinham em seu centro a teoria das ordens arquitetônicas, entre os quais encontram-se obras como I cinque ordini d'architettura, de Giacomo Barozzi Vignola (1507-1573); Principii di architettura civile, de Francesco Milizia (obra em três tomos); Desprincipes de l'architecture, de la sculpture et de la peinture et d'autres arts qui en dépendent avec un dictionaire destermes propes à chacun de ces arts, de Félibien; e Nuovo corso d'architettura civile dedotta daimigliorimonumentigreci,romani, italianidel cinquecento, de Antonio Ginesi.

No grupo dos livros técnicos encontram-se alguns bastante úteis, como o manual ricamente ilustrado Traité sur l'art de la charpente, théorique et pratique, de J. Ch. Krafft, obra trilingüe (francês, inglês e alemão) que trata principalmente da carpintaria de telhados, desde as formas mais simples às mais sofisticadas; o livro de Donnet et Orgiazzi (continué par Kauffmann). Architectonographie des théâtres de Paris ou parallèle historique et critique des édifices considérés sous le rapport de l'architecture et de la décoration; e um manual chamado Architecture de Bullet, ou le nouveau Bullet de la ville et des campagnes, cujo subtítuloéesclarecedor: "Obra indispensável aos arquitetos, mestres de obras, empreiteiros, aparelhadores, verificadores, agrimensores, operários, e para a verificação dos trabalhos dos particulares que mandam construir".

Os livros orientados para a formação do arquiteto e classificados aqui como exemplares já foram acima referidos, pois todos eles dizem respeito à arquitetura italiana, como Palais, maisons et autres édifices modernes, de Percier et Fontaine, e Architecture toscane, de Grandjean de Montigny.

Completam a série dedicada à arquitetura os livros Remarques sur l'architecture des Anciens, de Winckelmann, e Histoire de la vie et des ouvrages des plus célèbres architectes du XI e siècle jusqu'à la fin duXVIII", de Quatremère de Quincy, obras de caráter histórico que se complementam; a primeira trata dos estilos antigos, e a segunda biografa os arquitetos 
[12] Apud Rios Filho, Adolfo Morales de los. O ensino artístico. Subsídios para a sua história. Rio de Janeiro: $\mathrm{S}$. N., 1938, pp. 92-93. modernos mais importantes desde Buschetto, do século XI, até Soufflot, autor do projeto da igreja de Sainte-Géneviève, obra que o próprio Quatremère de Quincy adaptou transformando-a no Panthéon, depois da Revolução de 1789.

Há uma adequação bastante razoável entre o conjunto de livros dedicados à arquitetura e o que era previsto para seu ensino nos estatutos:

O estudo da arquitetura, ou da ciência da arte de edificar, segundo as regras e proporções determinadas, será teórico e prático. O professor ensinará cronologicamente a mudança de gostos e estilos que tem experimentado a arquitetura, desde a sua mais antiga origem até o seu estado florescente, tendo sempre em vista o conhecimento dos diversos modos de arquitetura adotados pelos gregos e romanos dos quais vários mestres dos séculos $X V$ e $X V I$ a exemplo de Vitrúvio, e, segundo a doutrina, compuseram as diferentes ordens de arquitetura; mas, para evitar todo sistema a este respeito, fará conhecer donde ele as tem coligido, dando somente aos discípulos exemplos extraídos dos monumentos existentes na Grécia e na Itália, e as cinco ordens de arquitetura de Vignola. Passar-se-á depois à aplicação destes diferentes modos às partes dos edifícios, seguindo-se o estudo da construção considerada debaixo de todas as suas relações, isto é, das partes que pertencem à composição, proporção e decoração dos edifícios em geral; e por isso é de grande importância que os discípulos da classe de arquitetura se apliquemao desenho de figura o ornatos, para se dirigirem com boa escolh a na parte decorativa de suas composições. Destes conhecimentos reunidos à teoria desta arte resulta o bom gosto de arquitetura, observando sempre as regras do referido Vignola ${ }^{12}$.

A série de livros dedicados à escultura é muito rica na parte dogmática e nos exemplos, mas bastante limitada no que diz respeito à técnica. Neste aspecto, o único livro que contém ensinamentos técnicos relativos à arte de esculpir é Due trattati di Benvenuto Cellini, obra já bastante antiga, que havia sido reeditada em 1811, com uma parte dedicada à ourivesaria e outra à escultura.

As obras que podem ser ditas dogmáticas são também exemplares e históricas, já que trazem consigo inúmeras reproduções de escultura antiga e moderna. Nesta série, Winckelmann também se destaca com Histoire de l'art chez les Anciens, que se completa com dois outros livros ricamente ilustrados: Monumenti antichi inediti, dele próprio, e Ricerche sopra un Apolline delle villa dell'eminentissimo sig. cardinale Alessandro Albani, do padre Stefano Raffei. Monumenti antichi é uma espécie de suplemento de Histoire de l'art. É composto por dois volumes em grande formato, contendo um tratado e 208 reproduções de frisos, baixos relevos, vasos e estátuas, com textos explicativos das imagens gravadas. O livro de Raffei é declaradamente um comple- 
mento desse último: "Para servir de suplemento à obra Monumenti antichi inediti de Giovanni Winckelmann", e contém reprodução gravada não apenas do Apolo referido no título, acompanhada de uma dissertação, mas também de outras estátuas e baixos relevos da vila do cardeal Albani. São ao todo sete dissertações acompanhadas das reproduções das obras analisadas. O livro de Quatremère de Quincy Monuments et ouvrages d'art antiques restitués d'après les descriptions des écrivains grecs et latins, et acompagnés de dissertations archeologiques pode ser agregado a esse conjunto, na medida em que restitui não apenas obras de arquitetura como o templo de Minerva na Acrópole, o túmulo de Porsenna e o fabuloso carro funerário que teria transportado o corpo de Alexandre da Babilônia ao Egito, mas traz também a reprodução do que teria sido a estátua de Minerva em ouro e marfim realizada por Fídias no Panteão.

E a esta série também se agrega Le Musée Français recueil complet des tableaux, statues et bas-reliefs qui composent la Collection Nationale, que, em cada um de seus quatro volumes, apresenta as mais preciosas esculturas que haviam sido trazidas para Paris depois das vitórias dos exércitos de Napoleão e que enriqueceram a já significativa coleção de esculturas presentes no Louvre, livro que merece um tratamento à parte ${ }^{13}$.

Além destes, dedicados à escultura antiga, há também três livros de exemplos que tratam da arte francesa: Recueil de costumes français, ou Collection des plus bellesstatues et figures françaises, des armes, des armures, des instruments, des meubles, etc., dessinés d'après les monuments, manuscrits, peintures et vitraux, depuis Clovis jusqu'à Napoléon, de Rathier \& Beaumier; Recueil desfigures, groupes, thermes, fontaines, vases, statues, et autres ornemens de Versailles tels qu'ils se voyent à présent dans le Chateau $\mathcal{E}$ Parc, de Simon Thomasin; e Antiquités de la France, de Clerisseau.

Ainda no que diz respeito à escultura destacam-se dois livros dedicados a artistas dos mais modernos:Intera Collezione dituttele opere inventata e scolpite dal Cav. Alberto Thorwaldsen (1768-1844); e uma biografia do escultor italiano Antonio Canova (1757-1822), assinada também por Quatremère de Quincy, mas que contém apenas uma ilustração.

Para coroar esse segmento, a biblioteca possuía a série de livros do conde Leopoldo Cicognara Storia della scultura dal risorgimento in Italiafino al secolo di Canova. Obra em sete volumes, acompanhada de livro de gravuras em grande formato, doados em 1859 por Araújo Porto-Alegre.

Os livros da Baiba dedicados à escultura formam um magnífico conjunto de publicações, que compendiam os maiores tesouros da arte antiga e moderna, venerados pela cultura neoclássica dos séculos XVIII e XIX.

Na parte dedicada à pintura, há que destacar o livro já referido de Félibien, Des principes de l'architecture, de la sculpture et de la peinture que,
[13] Ver Gomes Júnior, G. S. "Le musée français: guerras napoleônicas, coleções artísticas e o longínquo destino de um livro". Anais do Museu Paulista, v. 15/1, São Paulo, Museu Paulista, 2007 . 
como indica o título, serve a todas as áreas. E também uma obra castelhana, El Museo Pictórico y la escala óptica, de Palomino de Castro, cujo primeiro tomo intitula-se Theoria de la pintura, en que se discribe su origen, essencia, especies, y qualidades; e o segundo, Prática de la pintura, en que se retrata el modo de pintar à el olio, temple,y fresco. Estes dois livros são compêndios dos saberes acadêmicos sobre as artes do desenho.

Havia também na Baiba uma série de livros, dedicados ao desenho, em que se destacam os tratados de perspectiva:Direzioni de la prospettiva teórica, de Bibiena (Ferdinando Galli), Traité de perspective linéaire à l'usage des artistes, de Charles Choquet, Perspectiva pictorum, et architectorum, de Putei (Andrea Pozzo), Élémens de perspective pratique à l'usage des artistes, de Pierre-Henri Valenciènes, Elementi di perspettiva secondo li principii di Brook Taylor, con varie aggiunte spettantiall'ottica e alla geometria, de François Jacquier.

Outra série que é comum à formação de pintores e escultores é a que trata de anatomia e fisiologia das paixões, como Anatomie de formes extérieures du corps humain, appliquée à la peinture, à la sculpture et à la chirurgie, do médico P.-N. Gerdy; e Études des passions appliquées aux beaux-arts, de J.-B. Delestre. O livro de Gerdy tem caráter bastante prático, voltado para a descrição das formas exteriores e de seus fundamentos anatômicos. Já o livro de Delestre é mais filosófico. É um tratado sobre as paixões com o objetivo de instruir os artistas para lidar com as expressões de desejo, inquietude, cólera, ódio, amor, dor física, dor moral, satisfação, medo, coragem, furor, raiva, desespero; e o livro se completa com dois longos estudos sobre o gesto e o caráter. Mas, apesar de ter como objetivo servir ao artista para a representação gráfica das formas pelas quais as paixões se expressam no homem, não possui qualquer tipo de exemplificação, é um livro exclusivamente de texto. Seu esforço intelectual remonta aos antigos, particularmente a Aristóteles, e vai ao encontro do materialismo psicológico dos ideólogos, que tiveram em Destutt de Tracy (17541836), seu principal formulador no início do século XIX.

Esses dois livros se alinham com Les proportions du corps humain, mesurées sur les plus belles figures de l'Antiquité, de Gérard Audran, já referido acima, que é um guia prático de estudo da anatomia baseado nas principais esculturas da Antigüidade.

As obras relacionadas à formação do pintor que podem ser ditas exemplares são diversas. A coleção mais rica de imagens gravadas é sem dúvida a de Le Musée Français (1803), que é dividida em "Tableaux d'Histoire", "Tableaux de Genre et Portraits" e "Tableaux de Paysages, Marines et Vues", além das estátuas antigas. Há também um livro intitulado Galerie Aguado: Choix des principaux tableaux de la galerie de Mr.le Marquis de las Marismas de Guadalquivir (1839), que é uma boa coleção de pintura espanhola, que corresponde na época 
ao recente interesse que os espanhóis conquistaram no âmbito do judicioso gosto francês.

No campo particular do retrato destacam-se três livros de exemplos: Museo Fiorentino che contiene i ritrati de' pittori, de Francesco Moücke, livro que apresenta uma série de gravuras de auto-retratos de artistas das coleções florentinas; e também Portraits de tous les souverains de l'Europe et des hommesillustres modernes, de Mme. Meyer, queéclaramente um livro encomiástico, provavelmente financiado por subscrições, que foi atropelado pelos acontecimentos históricos. É um livro contendo 109 retratos de soberanos - sete reis e três imperadores, inclusive d. João VI - , ministros, generais, alta nobreza européia da segunda década do século XIX, incluindo muitas figuras já desaparecidas ou que caíram em desgraça depois das derrotas de Napoleão. E a estes se agrega um livro português intitulado Retratos e elogios dos varões e donas que ilustraram a nação portuguesa em virtudes, letras, armas e artes.É obra inicialmente publicada em fascículos, realizada por uma certa Sociedade Philopatrica, composta entre outros por Pedro José de Figueiredo, Mariano da Conceição Vellozo e José da Cunha Taborda. Esse livro perfaz uma verdadeira história de Portugal por meio de seus grandes nomes, desde o Infante D. Henrique até figuras de destaque de meados do século XVIII.

Com estas três obras e mais os retratos reproduzidos nos quatro volumes de Le Musée Français, pode-se dizer que o aluno da Aiba possuía uma riquíssima coleção de retratos oficiais ou encomiásticos como exemplos para aquela que era uma das partes fundamentais da profissão do pintor, a arte do retrato, da qual geralmente obtinha parte significativa de seu sustento. Além disso, as centenas de personagens retratados nos livros poderiam servir também como subsídio para a pintura de história, na qual muitas vezes é necessário tomar de empréstimo as fisionomias de certos personagens quando o objetivo é reconstituir acontecimentos solenes ou heróicos.

A biblioteca possuía também uma série de obras que podem ser ditas de referência. Dicionários, como o excelente Dictionaire des beauxarts de Millin, no qual alguns verbetes são verdadeiros tratados históricos, arqueológicos e estéticos; e o superficial mas informativo Dictionaire des artistes de l'école française de Gabet. Nessa rubrica, encontram-se também livros de geografia, como o Tratado completo de cosmografia e geografia histórica, de Casado Giraldes, e o Dictionnaire universald'histoire etgeographie, de Bouillet. Destacam-se também livros de viagens, como o Voyage autour du monde sur la corvette La Favorite, de Laplace; e outros livros de título parecido, em geral acompanhados com mapas das regiões percorridas por corvettes ou frégates francesas, que exploraram o mundo com a finalidade de reatar as relações comerciais depois do longo período de isolamento por que a França passou até a derrota de Napoleão. Entre estas viagens, há também outra, de 
[14] Frei Mariano da Conceição Velloso (1741-1811), nascido em Minas Gerais, foi um dos mais destacados representantes da geração ilustrada formada no fim do século XVIII, que serviu o império português com seus estudos de botânica e técnicas agrícolas - além de Florae fluminensis (1790), publicou também Fazendeiro do Brasil (1798-1806) - estimulado pelo vice-rei Luís de Vasconcelos, no Rio deJaneiro, e depois na esclarecida gestão de d. Rodrigo de Souza Coutinho, ministro dos negócios do Império, que o trouxe a Lisboa (Ver Dias, Maria Odila Leite da Silva. "Aspectos da Ilustração no Brasil". RIHGB, vol. 278, jan.-mar. 1968).
[15] Porto-Alegre, M. A. "Biblioteca da Academia”. In: Galvão, A. (org.). "Manuel de Araújo Porto-Alegre: sua influência na Academia Imperial das Belas-Artes e no meio artístico do Rio de Janeiro", op. cit., p. 79. interesse mais propriamente arqueológico, intitulada Voyage de la Troade, de Lechevalier, que corresponde a uma expedição tão típica da época (1785/1786) em busca da localização exata de Tróia; o quarto volume desta viagem é um Recueil des cartes, plans, vues et médailles. Este livro faz par com Vues des sites les plus célèbres de la Grèce antique, de Théodore Aligny, que é livro rico em imagens de paisagens e ruínas das regiões mais famosas da Grécia.

Mas chama a atenção o fato de haver poucos exemplares de obras de viajantes e naturalistas que percorreram o Brasil, ciclo que produziu uma abundante literatura riquíssima em imagens. Sobre a flora e a fauna brasileiras há somente Ornithologie brésilienne ou Histoire des oiseaux du Brésil, remarquables par leur plumage, leur chant ou leurs habitudes, de Jean Descourtilz; e Florae fluminensis do botânico — nascido em Minas Gerais — José Mariano da Conceição Velloso ${ }^{14}$. E nada de Spix \& Martius, de zu Wied Neuwied, ou de Saint-Hilaire. E nem mesmo os livros de cenas brasileiras de Hippolyte Taunay e Ferdinand Denis. Até 1859, nem Félix-Émile Taunay, nem Araújo Porto-Alegre, os construtores da biblioteca, cuidaram de a ela incorporar as obras desses dois autores, por mais articulados que estivessem à colônia dos artistas franceses no Brasil.

Sobre essa lacuna é importante observar algo que Porto-Alegre escreveu sobre a necessidade de renovação da biblioteca em 1855 , época em que a Academia já havia alcançado alguma maturidade e não estava mais sob a hegemonia dos artistas franceses que fundaram a instituição. Entre os escritos que deixou sobre a renovação da biblioteca, Porto-Alegre propõe o projeto da formação de coleções que teriam utilidade não só para o ensino, mas também para servir de subsídio à indústria. E assim explicita:

Estas coleções serão de um preço incalculável no futuro, e poderão ser agrupadas em livros da maneira seguinte: $1^{\circ}$ - Retratos históricos de todas as épocas do Brasil. 2- Retratos das notabilidades do país. $3^{0}$ - Estampas gravadas e litografadas no Brasil. $4^{0}$ - Desenhos originais de brasileiros e sobre o Brasil. $5^{\circ}-U$ sos e costumes desde os tempos coloniais. 6- Estudos sobre os nossos indígenas. $7^{\circ}$ - Vistas do Brasil. 8-Usose costumes das províncias. 9- Festas nacionais. 10- - Quadros históricos. $11^{0}$ - Fantasias dos artistas brasileiros. $12^{\circ}$ - Flores e animais do Brasil. E outros com estampas avulsas de todos os países para auxílio da história e da reprodução $0^{15}$.

A primeira coisa a se observar é que a proposição de tais coleções confirma a inexistência de materiais desse gênero no acervo da biblioteca, o que leva a pensar que a biblioteca, assim como a Academia em suas primeiras três décadas, não tinha pretensões claramente nacionais. E que o projeto de formar tais acervos pode ser visto como o início da nacionalização da Academia, em época em que a geração de mes- 
tres franceses já havia dado lugar aos seus sucessores brasileiros. Parece claro que o objetivo era criar na biblioteca uma memória pictórica brasileira. Como Varnhagem ou Januário da Cunha Barbosa, com seus florilégios de poesia, Porto-Alegre quis reunir em coleções a arte brasileira, e ver o Brasil documentado pela arte. Isto tudo, em 1855.

\section{SERVENTIA PROVÁVEL}

A biblioteca da Academia Imperial das Belas-Artes, apesar de pequena, era prática para o ensino das artes do desenho, cuja pedagogia estava fundada, sobretudo, no exemplo. Cabelembrar que a biblioteca fazia par com a Pinacoteca, que começou a ser formada com os 42 quadros (entre os quais muitas cópias) trazidos por Lebreton em 1816, para servirem de exemplo no processo de ensino.

Boa parte da formação do artista estava baseada no exercício continuado da cópia das pinturas da Pinacoteca ou das estampas e gravuras da biblioteca. O que não era específico do ensino artístico no Rio de Janeiro, mas característica geral das academias. Comolembra Pevsner, a Academia de Pintura e Escultura francesa, desde o tempo de Le Brun, e até mesmo no século XIX, comportava duas classes, uma elementare outra superior, entre as quais se dividiam três fases do aprendizado: primeiro apenas a cópia de desenhos e pinturas, depois o desenho a partir de moldes em gesso e esculturas antigas e, por fim, o desenho a partir de modelos vivos ${ }^{16}$.

O fato de Taunay ter utilizado em suas traduções o livro de Gérard Audran Les proportions du corps humain, mesurées sur les plus belles figures de l'Antiquité é um bom indicativo dessa perspectiva pedagógica. O discurso preliminar que acompanha os desenhos gravados no livro de Audran é talvez o exemplo mais precioso das operações mentais que eram a base do sistema acadêmico. No discurso, parte-se do pressuposto de que "a perfeição da arte consiste em bem imitar a natureza;e parece inútil consultar outro mestre que não seja ela”. Dado este axioma, parece suficiente a recomendação de se trabalhar a partir do modelo vivo, mas o texto imediatamente começa a colocar em questão esta idéia. Em primeiro lugar, pelo fato de raros modelos vivos apresentarem todas as partes igualmente belas ou justamente proporcionadas - e aqui estamos de novo em plena tópica retórica fundada na anedota da relação de Zeuxis com as virgens de Crotona. Caberia então, para corrigir os erros da natureza, escolher as partes mais belas em vários modelos. Mas será isso possível? O artista não correria o risco de cometer erros de discernimento pelo fato de ser formado em um determinado lugar e de ter, portanto, os mesmos preconceitos de seu país de origem e de sua Escola, no que diz respeito à beleza? Ou mesmo de cometer erros em função dos preconceitos de seu tempera-
[16] Pevsner, Nikolaus. Les académies d'art. Paris: Gérard Monfort, 1999 [1940], p. 95. 
[17] Audran, G. Les proportions du corps humain, mesurées sur les plus belles figures de l'Antiquité. Nouvelle Édition dédiée aux Écoles centrales. Paris: chez Joubert, 1801 .

[18] Ibidem.

[19] Ibidem. mento particular? É em função da particularidade do temperamento de um artista que se costuma dizer que

um Pintor pinta a si mesmo em suas obras; e se tivermos suficiente acuidade ou reflexão poderemos encontrar nelas suas inclinações predominantes. Um sentimento inato, do qual quase sempre se ignora a causa, determina sua escolha, e o conduz a conformar suas figuras e o aspecto das pessoas pelas quais ele se sente atraído, ou com as quais ele costuma viver ${ }^{17}$.

Da Escola, que modela o gosto e a visão geral do artista, e de seu próprio temperamento, nasce a maneira que o particulariza. E, "aquilo a que se dá o nome de maneira em Pintura é com muita freqüência um defeito, um modo de trabalho que em princípio nos agrada, que se forma pela força do hábito, e que termina por ser invisível aos nossos próprios olhos"18.

E qual é o antídoto contra estes riscos, já que a imitação da própria natureza traz consigo tantos problemas? A resposta é simples: "Consultar o Antigo com total confiança"19! Os antigos não trabalharam em qualquer país, mas na Grécia, que era fértil em belezas, ou na Itália, que tinha o domínio do mundo, e tudo que era raro, bom e belo estava lá, por toda parte e em abundância. E, além disso, eles aprenderam a dominar seus temperamentos, suas paixões e, com isso, souberam evitar todos os vícios que poderiam derivar seja do meio, seja do indivíduo, e produziram uma arte que, depois de tantos séculos, continua a ser admirada por sua rara perfeição. Aequação inicial tem dessa forma o seu fecho. A regra fundamental da arteé a imitação da natureza, mas, diante dos problemas colocados em tal operação, o melhoré imitar os antigos, quejá souberam tirar dela os melhores exemplos. E assim o livro deAudran se justifica: as figuras reproduzidas - Hércules, dito o Farnese; Laocoonte; Piramôs no JardimLudovise; Antínoos, sobrenomeado oAdmirável; a Pastora Grega;Vênus Afrodite, dita de Médicis... - vistas por todos os lados e cuidadosamente medidas, são os melhores exemplos para o estudante das belas-artes, é com elas que se deve aprender a imitação da natureza!

Apesar de seus limites, a biblioteca da Aiba estava perfeitamente aparelhada para responder a tais propósitos, e a relativa rapidez com que a Academia produziu bons frutos é um sinal de que os métodos expostos em seus livros ou que se serviram de seus livros tinham lá sua eficácia.

Stendhal, nas críticas aos salões que escreveu em Paris nos anos de 1820 , inventa uma anedota que pode aqui servir de conclusão, mas não para acompanhá-lo em sua contundente ironia:

Coloque na prisão o mais ordinário dos homens, o menos familiarizado com todas as idéias sobre arte e literatura; em uma palavra, um desses igno- 
rantes desocupados que se encontram em grande número numa grande capital; e, logo após ele ter sentido a primeira onda de medo, diga a ele que reconquistará a liberdade se for capaz de expor no Salão uma figura nua, perfeitamente desenhada por meio do sistema de David. Você ficará totalmente surpreso ao ver o prisioneiro, submetido a tal prova, de volta ao mundo ao fim de dois ou três anos. Isso se deve ao fato de que o desenho correto, científico, imitação do antigo, como pressupõe a Escola de David, é uma ciência exata, da mesma natureza que a aritmética, a geometria, a trigonometria, etc.; donde se conclui que, com uma paciência infinita [...], chega-se em dois ou três anos ao conhecimento e à capacidade de reproduzircomo pincel a conformação e a posição exata dos cem músculos que recobrem o corpo do homem²o.

É evidente que isto é apenas uma anedota, que, no entanto, não deixa de conter elementos para que se possa entender a produtividade que o ensino acadêmico pode obter com sua seca e minuciosa pedagogia.AAcademia das Belas-Artes do Rio de Janeiro, por meio da biblioteca, entre outros instrumentos pedagógicos, buscou proporcionar os recursos para que os jovens vocacionados para a arte saíssem de suas prisões, à custa evidentemente de uma paciência infinita. A prisão de sua possível condição social, a prisão de seu exílio em terra inculta como a distante Guanabara.

Foi com instrumentos dessa natureza que se criou uma Escola, produtora inicialmente de obras de qualidade média. Aquelas pelas quais, segundo o mesmo Stendhal, "deve-se julgar o progresso ou a tendência de uma escola" ${ }^{21}$. Nos idos de 1860, quando começou a surgir a nova geração de artistas formados pela Aiba, os prisioneiros que saíam da cadeia já eram capazes, vez por outra, de apresentar algo mais do que apenas obras de qualidade média.

\section{INTRIGANTE DECORAÇÃO}

Para encerrar este artigo, cabe chamar a atenção para um elemento da ornamentação da sala da biblioteca que não é referido nem por Porto-Alegre, nem por Gonzaga Duque em seus comentários sobre a pintura do teto realizada por Léon Pallière. A alegoria das belas-artes que ocupava o centro do teto se completava com medalhões contendo retratos de artistas célebres. Quem fala sobre isso é Moreira de Azevedo na descrição que fez do palácio da Academia, na série de livros intitulados Pequeno panorama ou descrição dos principais edifícios da cidade do Rio de Janeiro, publicados entre 1861 e 1867. Eram retratos de catorze pintores que formavam uma espécie de panteão a inspirar as atividades da Academia:Apeles, Da Vinci, Rubens, Dürer, Velázquez, Andrea del Sarto, Murillo, Van Dyck, Michelangelo, Rafael, Poussin, Tinto-
[20] Stendhal, "Critique amère du Salon de 1824 par M.van Eube de Molkirk". In:Salons.Édition, introduction et notes de S. Guégan et M. Reid. Paris: Gallimard, 2002,pp. 78-79.

[21] Idem, "Exposition de tableaux au Louvre", p. 51. 
[22] O mural de Delaroche ocupa um espaço de 27 metros em uma espécie de salão nobre da Escola de BelasArtes, no qual eram realizadas as cerimônias de premiação dos artistas laureados nos concursos da Academia.A pintura foi danificada por um incêndio, em 1855, e Delaroche prontificou-se a restaurá-la mas faleceu logo em seguida, em 1856 , e o trabalho foi concluído por Robert-Fleury.
[23] Sobre o Hemiciclo de Delaroche, Delécluze escreveu uma notícia explicativa em que, além da descrição física da pintura, identifica os personagens retratados (ver L'Hémicycle du Palais des Beaux-Arts. Peinture murale exécutée par Paul Delaroche. Notice explicative. Paris: Chez Goupil, s./d.). Sobre os debates e as imitações que o Hemiciclo suscitou, ver Haskell, Francis. "Hiérarchie et subversion". In: $L a$ norme et le caprice. Paris: Flammarion, 1983. retto, Ticiano e Rembrandt. A lista é de grande interesse, pois indica um panteão de artistas e um cânone de obras que, muito provavelmente, não seria possível nos primeiros tempos da instituição, pois pressupõe as mudanças de gosto que se operaram na primeira metade do século XIX, e tornaram mais aceitáveis nas rotinas acadêmicas os adeptos da cor, sempre opostos aos defensores da linha. A forte presença de artistas de Veneza, Antuérpia, Amsterdã e Sevilha — Ticiano, Tintoretto, Rubens, Van Dyck, Rembrandt, Murillo e Velázquez - é sinal desse novo estado, sendo que os cinco últimos são do século XVII, época dita barroca.

O programa iconográfico completo da sala da biblioteca da Aibaé muito provavelmente caudatário da famosa pintura que Paul Delaroche (1797-1856) realizou no Hemiciclo da Escola de Belas-Artes em Paris, aberto ao público em 1841 depois de quatro anos de trabalho ${ }^{22}$. Delaroche, por sua vez, deixou clara no Hemiciclo sua dívida com a Apoteose de Homero, pintada por Ingres, catorze anos antes, para o teto de uma das salas do Louvre. Tanto Delaroche quanto Ingres articularam em suas pinturas elementos alegóricos com retratos realistas mas, enquanto este fez figurar em torno de Homero representantes de todas as artes, aquele restringiu seu panteão aos praticantes das artes do desenho. Delaroche incluiu em sua pintura uma verdadeira multidão de artistas: Ictinos, Fídias e Apeles, representando a arquitetura, a escultura e a pintura da Antiguidade grega, ocupam três tronos no centro da grande pintura mural; e estão cercados por quatro alegorias femininas, que representam a arte gótica, a arte grega, a arte romana e a arte renascentista. Entre essas alegorias, destaca-se bem ao centro uma quinta figura feminina representando o Gênio das Artes. Os artistas modernos (do século XIII ao XVII) foram divididos por características de estilo ou de gênero em duas grandes alas. À esquerda, entre aqueles que podem ser ditos coloristas, figuram Correggio, Veronese, Antonello de Messina, Murillo, Van Eick, Ticiano, Terborch, Rembrandt, Van der Helst, Rubens, Velázquez, Van Dyck, Bellini, Giorgionee, até mesmo Caravaggio. Entre os pintores de paisagens, estão Ruisdael, Paul Potter, Claude Lorain e Gaspard Pous$\sin$. $\mathrm{Na}$ ala oposta, foram agrupados os grandes desenhistas, adeptos da linha: Nicolas Poussin, Giotto, Cimabue, Andrea del Sarto, Michelangelo, Masaccio, Perugino, Rafael, Giulio Romano, Mantegna, Fra Bartolomeo, Domenichino, Da Vinci, Dürer, Del Piombo e Orcagna. Por fim, um outro grupo de pintores e gravadores: Le Sueur, Holbein, Edelinck, Raimondi e Fra Angelico ${ }^{23}$. A concepção é majestosa, estática no centro e movimentada nas alas laterais, onde os artistas, alguns sentados, outros em pé, relacionam-se uns com os outros por meio de conversas e olhares. A referência à Escola de Atenas, de Rafael, é também explícita, principalmente no que diz respeito ao formato 
semicircular - esticado horizontalmente no caso de Delaroche, em que se vê uma pequena distância entre o primeiro e o último plano, aprofundado no caso de Rafael, em que os planos se multiplicam até se perderem no ponto de fuga no centro da composição - e à situação interativa dos personagens.

O Hemiciclo da Escola de Belas-Artes em Paris pode ser entendido como um manifesto, no qual o próprio Delaroche, no auge de sua fama, explicitava sua posição intermediária na Escola Francesa, na grande divisão que se estabeleceu entre Ingres e Delacroix - entre homeristes e shakesperiens, no dizer do crítico Etienne-Jean Delécluze ${ }^{24}$. Desde 1832, Delaroche ocupava a décima terceira cadeira de pintura na Academia de Belas-Artes, e o Hemiciclo foi a oportunidade de demonstrar em um grande mural, onde figuram ao todo 75 personagens, a grande flexibilidade de seu talento, expressa na capacidade de transitar entre estilos e maneiras, sendo fiel à linha ao retratar os grandes desenhistas e ao seu oposto ao compor as figuras dos grandes coloristas. Com isso, parece dizer que a Escola, depois de longo conflito, estava finalmente reconciliada.

Como observou Delécluze, na notícia explicativa que escreveu sobre o Hemiciclo, a pintura representa uma espécie de tribunal, presidido por Fídias, Apeles e Ictinos, tendo como membros do júri a plêiade de artistas acima elencados. Por estarem lá, em relativo equilíbrio, representantes de todas as grandes tendências, supõe-se que a Academia não terá comportamento sectário nem cometerá injustiças. O Hemiciclo é, por assim dizer, a apologia das vantagens do juste milieu. Depois dessa pintura-manifesto, a Academia estava pronta para receber em seu seio, em 1857, o quase sexagenário shakesperien Eugène Delacroix, que ocupou a mesma décima terceira cadeira depois do falecimento de Delaroche.

Se Araújo Porto-Alegre, que voltou da Europa em 1837, onde esteve durante seis anos, até então não havia tido oportunidade de conhecer pessoalmente o Hemiciclo, Léon Pallière, ao contrário, foi pensionista da Aiba no Velho Continente, no início da década de 1850 , quando a visita ao recinto pintado por Delaroche era uma espécie de obrigação para artistas e amadores em trânsito por Paris. E é provável que ambos possam ter tido notícias acerca dos inúmeros debates sobre as injustiças cometidas por Delaroche ao preterir determinados artistas e incluir outros.

O empreendimento de Porto-Alegre e Léon Pallière não pode ser colocado na cota da tendência, dita brasileira, de macaquear tudo que é estrangeiro, pois o Hemiciclo de Delaroche teve outras imitações mais destacadas:em Antuérpia, Nicaise de Keyser se inspirou em Delaroche ao pintar um mural dedicado à glória dos artistas locais no museu da cidade; e em Londres, no memorial em homenagem ao príncipe
[24] A associação de Shakespeare aos românticos tornou-se um verdadeiro dístico, nos idos de 1824, por meio da crítica rotineira de Delécluze no Journal des Debats, periódico de grande influência na época. A oposição entre homéristes e shakespeariens, mobilizada no discurso sobre arte, é caudatária do contraste entre as literaturas meridionais e do Norte (homéricas e ossianescas) formulada por Mme. de Staël. Apoteose de Homero, de Ingres, que era amigo de Delécluze, apresentado em 1827, é devedor dessa oposição. Além de sua atividade de crítico de arte, desde 1820, Delécluze reunia semanalmente em sua casa um grupo seleto de amigos, com os quais tratava variados assuntos de artes e letras, $e$ Shakespeare foi tema constante entre eles (também Byron), de leitura e discussão (Ver Baschet, Robert. "Introduction”. In: Delécluze. Carnet de route d'Italie (1823-1824). Impressions romaines. Paris: Boivin Éditeurs, 1942, p. 1. 
[25] Ver Haskell, op. cit.

[26] Porto-Alegre, M. de A. "Exposição de 1843 ". Minerva Brasiliense, $\mathrm{n}^{\circ} 5$, 10 de janeiro de 1844, p. 149. Trata-se aqui do segundo artigo de Porto-Alegre sobre a exposição, o primeiro apareceu no número anterior da revista $e$ se intitula "Exposição pública".
[27] Idem, "Algumas idéias sobre as Belas-Artes e a indústria no Império do Brasil". Guanabara. Rio de Janeiro, 1851,p.110.
Albert, marido da rainha Vitória, também foi representado um panteão de artistas célebres em todos os tempos, dessa vez não em pintura mas em altos relevos, esculpidos por Henry Hugh Armstead ${ }^{25}$.

De qualquer forma, Porto-Alegre estava bastante bem informado sobre o que se passava em Paris, e particularmente sobre a arte de Delaroche, tanto que, na crítica que publicou na revista Minerva Brasiliense a propósito da exposição de 1843, acontecida no Rio de Janeiro, teceu alguns comentários sobre a arte do pintor francês. Só que nessa data sua tolerância aos adeptos da corera um tanto limitada, a ponto de dizer que "la couleur - é a peste maior que tem aparecido, e que tem afastado da senda do belo tantos homens de gênio" 26 . E, no mesmo artigo, ressalta o fato de Delaroche ter abandonado "la couleur" nos seus últimos quadros, dedicados a Carlos I e a Cromwell. Mas, por prudência, Porto-Alegre não deixa de fazer referências a grandes coloristas como Ticiano, Rubens, Van Dyck, Rembrandt, Veronese, Murillo, ressaltando sempre a diferença entre esses mestres e seus imitadores cujo trato pictórico lembra as "pastas de tinta colocadas na porta de um tintureiro".

E, para lembrar a todos que foi aluno de Gros, também ele um colorista, Porto-Alegre relata alguma coisa sobre sua pedagogia: "[Gros] nunca nos ensinou a colorir; o que mais insistia era sobre a construção, sobre o conhecimento da mecânica do corpo humano, e sobretudo o desenho", além, é claro, do estudo das estátuas antigas. O que é um resumo da pedagogia neoclássica. E, para arrematar, conclui que o colorismo em si agrada apenas o "homem primitivo", e comemora o fato de não termos ainda regredido a esse ponto: "em geral há muito bom senso no Brasil"!

O que pode ser notadoéque Porto-Alegre, entre as posições defendidas nesse artigo de 1843 e aquelas dos anos 1850 quando foi realizada a pintura do teto da biblioteca, estava a operar uma ligeira e discreta conversão. O que vai ficar evidente no artigo "Algumas idéias sobre as BelasArtes ea indústria no Império do Brasil", publicado na revista Guanabara em 1851. Esse artigo, dividido em três partes, apresenta umas tantas novidades, mas o que chama a atenção éo abandono de uma visão estática e universal da arte, em favor de reflexão de corte claramente relativista, que admite as mudanças de gosto no tempo e no espaço.

O que chama atenção nesse artigo é a articulação entre a arte e os outros elementos da vida social, o queéesboço de uma visão sistêmica da cultura:

nós temos balizas infalíveis para o pleno conhecimento do estado de um povo em qualquerépoca que seja, logo que soubermos do estado de um dos seus elementos de civilização: não há indústria sem comércio, não há filosofia sem ciências, e não hábelas-artessem literatura:este último elemento ésempreo maisfiel representante das idéias do tempo $[\ldots]{ }^{27}$. 
E o povo, que é uma categoria a todo tempo evocada no artigo, quanto mais mobilidade tiver mais fará surgir novas formas estéticas. Porto-Alegre contempla a história francesa e indica as constantes mudanças no plano das artes: a arquitetura gótica nos tempos feudais, o retorno aos ideais clássicos gregos, o estilo barroco e a volta ao classicismo nas vésperas da Revolução. E, em épocas mais recentes, as mudanças aparecem mais aceleradas:

À soberania burguesa, a realeza popular começa a desagradar; os espíritos rolam num mar de incertezas, num tormentoso provisório, e as artes se lançarão em diferentes vias: os teatros se ornarão de semilúneos, os lustres de caudas encarnadas, e os camarotes de ornatosárabes: durou essa confusão de 1833 a 1840 pouco mais ou menos; e eis que de repente surge o estilo borromínico, ou barroco, e passa a cidade de Paris e toda a França, e as nações que a imitam, a produzirem todos os objetos de indústria, e construírem salões naquele gosto, que poucos anos atrás era olhado como um delírio do pensamento humano, como uma aberração do gosto, e contrária a todos os princípios do belo e do sublime ${ }^{28}$.

O que Porto-Alegre não diz é que ele próprio, anos antes, escrevia estas mesmas coisas sobre o barroco, considerado "doutrina errônea", contrário às regras estáveis do belo, fruto de uma época que começou com a grande arte de Michelangelo, que foi seguido por uma "torrente de imitadores" que propagaram seus defeitos e degeneraram as artes ${ }^{29}$.

Poucos anos mais tarde em outro artigo, dessa vez publicado na Revista do Instituto Histórico e Geográfico Brasileiro, intitulado "Iconografia brasileira", na seção dedicada a [Mestre] Valentim da Fonseca e Silva, notável artista do Rio de Janeiro do tempo dos vice-reis, PortoAlegre começa exatamente por uma reflexão sobre as mudanças de critérios na apreciação das obras de arte:

Seria difícil há quinze anos fazer o elogio desse artista, sem desafiar os ânimos daqueles que seguiram a escola chamada clássica, aquela que foipropagada por Winckelmann e Rafael Mengs, exemplificada por David, Pompeu Battoni, Perciere Fontaine, exagerada por Camuccini, Valadiere Benvenuti. As crenças também se renovam no mundo artístico para justificarem o círculo vicioso de Vico: o barroquismo, condenado há quinze anos como um delírio do espírito humano, está hoje outra vez em voga; mas não é somente a moda, a deusa soberana dos espíritos volúveis, que concorre para as mudanças artísticas nos nossos tempos, mas sim aquele espírito de mobilidade da sociedade moderna, que faz hoje em cinco anos o que em outras eras se fazia em um século3o.
[28] Ibidem.

[29] Idem. "Exposição de 1843", op. cit., p. 150 .

[30] Idem. "Iconographia Brazileira". Revista do Instituto Histórico e Geográfico brasileiro, tomo XIX n ${ }^{\circ} 23$, 1856, p.369. 
Recebido para publicação em 15 de abril de 2008 .

\section{NOVOS ESTUDOS}

CEBRAP

81, julho 2008

pp. 157-177
Nesses textos da década de 1850 Porto-Alegre parece estar acertando o passo com as correntes em voga na Europa; e se mostra um pouco mais complexo na maneira que aborda os fenômenos artísticos e muito menos ortodoxo no que diz respeito às idéias, particularmente aquelas ligadas à pedagogia neoclássica. É possível dizer que o programa iconográfico da sala da biblioteca da Aiba, com a forte presença de artistas associados ao barroco, está articulado a essas mudanças no plano do pensamento e a uma certa adesão à mobilidade da sociedade moderna que coloca em questão as antigas regras fixas da arte.

Em certo sentido, pode-se dizer que a decoração do recinto da antiga sala da biblioteca tinha algo de inquietante para boa parte dos livros lá abrigados.

Guilherme Simões Gomes Júnioré professor do Departamento de Antropologia da PUC-SP. 